Chapman University

Chapman University Digital Commons

Psychology Faculty Articles and Research

Psychology

2011

\title{
"I Would Feel Uncomfortable if My Child's Teacher were Gay": Examining the Role of Symbolic Homophobia and Political Affiliation
}

Michael Moore

University of Michigan

Amy C. Moors

ChapmanUniversity, moors@chapman.edu

Follow this and additional works at: https://digitalcommons.chapman.edu/psychology_articles

Part of the American Politics Commons, Family, Life Course, and Society Commons, Gender and Sexuality Commons, Other Feminist, Gender, and Sexuality Studies Commons, Other Psychology Commons, Personality and Social Contexts Commons, Social Psychology Commons, Social Psychology and Interaction Commons, and the Women's Studies Commons

\section{Recommended Citation}

Moore, M.*, \& Moors, A. C. (2011). "I would feel uncomfortable if my child's teacher were gay": Examining the role of symbolic homophobia and political affiliation. Modern Psychological Studies, 17(1), 45-58.

This Article is brought to you for free and open access by the Psychology at Chapman University Digital Commons. It has been accepted for inclusion in Psychology Faculty Articles and Research by an authorized administrator of Chapman University Digital Commons. For more information, please contactlaughtin@chapman.edu. 


\title{
"I Would Feel Uncomfortable if My Child's Teacher were Gay": Examining the Role of Symbolic Homophobia and Political Affiliation
}

\author{
Comments \\ This article was originally published in a href="https://scholar.utc.edu/mps/vol17/iss1/7/">Modern \\ Psychological Studies, volume 17, issue 1, in 2011.
}

\section{Copyright}

The authors 


\title{
"I Would Feel Uncomfortable if My Child's Teacher were Gay": Examining the Role of Symbolic Homophobia and Political Affiliation
}

\author{
Michael Moore \& Amy Moors \\ University of Michigan
}

\begin{abstract}
Symbolic homophobia is a general negative disposition towards lesbian, gay, and bisexual individuals, which is demonstrated in symbolic forms of prejudice rather than overt actions. Stigma towards lesbian, gay, and bisexual (LGB) individuals has transformed from overt forms of prejudice to slightly less blatant more subtle forms in recent years (Schafer \& Shaw, 2009). Based on previous research, it is has also been shown that conservatives will have higher levels of symbolic homophobia. (Linneman, 2004), Thus, in order to assess the more nuanced forms of prejudice in relation to political affiliation, Study 1 created a scale to assess symbolic homophobia. In Study 2, experimental design was implemented to assess whether a positive description of a gay couple (compared to a positive description of a straight couple) lowers an individual's symbolic homophobia. The results of Study 1 suggest that the newly created symbolic homophobia scale is valid and those with conservative political ideology are more symbolically homophobic than liberals. Additionally, Study 2 found that being presented with a vignette of a gay couple lowers the participant's symbolic homophobia score.
\end{abstract}

Keywords: symbolic homophobia, prejudice, LGBT, political affiliation

"I Would Feel Uncomfortable if My Child's
Teacher was Gay": Examining the Role of
Symbolic Homophobia and Political
Affiliation Imagine living in a world where blue eyes are considered immoral or inherently deviant to many people. Although eye color is beyond one's control, some of society still deems an individual as disgusting merely from this trait. This scenario may seem strange but can be an everyday challenge for gay and lesbian people all over the world. Homophobia is popularly defined as people who have fear, hatred, and anger towards gay and lesbian people (Aguinaldo, 2008). This socially constructed term is evolving from the common usage of 'phobia' and is moving more towards homoprejudice (Ahmad \& Bhugra, 2010). Moreover, the term heterosexism describes this prejudice as oppression based on an ideological system that looks down upon any nonheterosexual form of behavior (Aguinaldo, 2008). Likewise, homophobia is also generally a form of prejudice that is culturally learned, which brings it away from the more common definition of a phobia (O'Brien, 2008).

Discrimination towards lesbian, gay, and bisexual (LGB) individuals has changed drastically over the years and has become less overt (Schafer, et al., 2009). When talking about LGB history and the gay civil rights movement, it is impossible to not mention the Stonewall Inn Riots of 1969. Police raids on bars that catered to the queer community used to be frequent. Haber (2009) suggests that the Stonewall Riots were one of the first times in US history that gays and lesbians stood up against government-sponsored persecution. From these riots came the rise of the gay liberation movement that helped change the public's opinion of gays and lesbians. Another major change for gay civil rights was the change of the Diagnostic and Statistical 
Manuel (American Psychiatric Association, 2000). From 1952-1973, homosexuality was pathologized and listed as a personality disturbance caused by a fear of the opposite sex (Haber, 2009). With the removal of homosexuality as a psychopathological disorder though, the anti-gay groups could no longer use psychology explicitly to say gay or lesbians have a mental dysfunction.

Although the gay liberation movement has made much progress, homophobia must be continually studied and eradicated. According to Aguinaldo (2008), there are negative ramifications on gay and lesbians' mental health from experiencing oppression and discrimination. From the feelings of prejudice, many gay people begin to internalize this homophobia (Clarke, Ellis, Peel, \& Riggs, 2010). This presents itself in the gay individual as general feelings of inadequacy, guilt, shame, lacking social value, and self-loathing (Aguinaldo, 2008; Clarke et al., 2010). Having these feelings of constant shame and guilt are detrimental to the physical and mental wellbeing. It should thus come to no surprise that gay men and women have higher rates of depression and anxiety (Igartua Gill, \& Montero, 2003). With these reasons, homophobia must be better analyzed.

O'Brien (2008) suggests that homophobia is developed from cultural experiences, thus, the present study creates a scale that can be used to analyze an individual's level of symbolic homophobia. Symbolic homophobia can be defined as a general negative disposition towards lesbian, gay, and bisexual individuals, which is demonstrated in symbolic forms of prejudice rather than overt actions. With the Stonewall Riots, removal of homosexuality as pathology from the DSM, and other gay civil rights accomplishments, homophobia has begun to become slightly more hidden within society and direct homophobia is becoming less politically correct.

Although there are other scales that exist to measure homophobia, the language used in these measures implies more overt forms of prejudice (e.g., Herek, 1988; Kite \& Deaux, 1986). For instance, some of the items in Herek's (1988) scale directly measure more overt forms of prejudice: "Lesbians just can't fit into our society" or "Lesbians are sick" (Herek, 1988). Since outward discrimination towards LGB individuals has become slightly less acceptable in our culture, (Schafer, et al., 2009) items created for the symbolic homophobic scale were less explicit. In other words, having a more nuanced scale that assess symbolic homophobia, will better measure people's attitudes towards LGBT people. This new scale is also modeled off of a similar and successful scale related to symbolic racism which assesses people's view towards race in much more underlying ways (Rabinowitz, Sears, Sidanius \& Krosnick, 2009).

The goal of this project is twofold and is split into two connected studies. The first part of this study is to create and analyze the validity of a scale that seeks to measures an individual's symbolic homophobia. To test this scale, it will be utilized to see if there is a significant difference between the scores of two known groups (conservatives compared to liberals). The second part of this study is to use this new scale in an experiment utilizing a person perception paradigm. The scale will be used to test the effects of either viewing a homosexual couple or a heterosexual couple vignette and how this affects the participant's symbolic homophobia score.

\section{STUDY 1}

Study 1 was designed for two main reasons. The first goal was to assess the validity and reliability of the newly created scale on symbolic homophobia. As stated, the goal of symbolic homophobia is to determine if someone is homophobic by asking more underlying questions instead of overt questions such as "Lesbians are sick" (Herek, 1988). The second goal of this scale was to determine whether homophobia is more prevalent between 
two separate political groups. Based on previous research, it is hypothesized that there difference between how liberals and conservatives see gay and lesbian people (Linneman, 2004), such that conservatives will have higher levels of symbolic homophobia.

\section{Method}

\section{Participants}

The sample for this study comprised of 49 participants who took part in an online survey. From these participants, $47.2 \%$ were males, $47.2 \%$ were females, and $3.8 \%$ were transgender. For political affiliation, $13.2 \%$ reported being conservative, $73.6 \%$ reported being liberal, and $13.2 \%$ did not report a political affiliation. The sample is considered a convenience sample because the participants were selected from a known group of people over a social media platform.

\section{Procedure}

The data for the survey was collected over an online survey tool, Qualtrics. The questionnaire asked ten specific questions about symbolic homophobia. The questions were randomized for each participant to counteract any ordering effects that could have arisen with the questions. Two demographic questions asked political affiliation (Liberal or Conservative) and the gender of the participants (Male, Female, or Transgender). The survey was distributed using an online social media site and was given haphazardly to a known social network.

\section{Measures}

The survey consisted of ten questions to identify the individual's score on symbolic homophobia. These questions were asked on a 4-point scale ranging from strongly agree to strongly disagree. Some items were on the positive end of the scale such as "I enjoy having friendships with gay and lesbian people" (see Appendix A). Whereas, some items endorsed higher symbolic homophobia, for instance, "I feel uncomfortable when I see a gay couple holding hands," "I believe being gay is fine as long as they keep it behind closed doors," and "Some gay people could be straight if they really wanted to be" (see Appendix A). With the participants' scores, a mean number was created that describes the participants' symbolic homophobia. When creating this score, the four positive questions were reversed coded so that all the questions went in the same direction. In the end, the lower someone's composited score, the more homophobic they were. The higher someone's score, the less the participant was homophobic.

\section{Results}

\section{Cronbach's Alpha}

To examine if scale items were reliable, an inter-item reliability assessment was performed. The symbolic homophobia scale showed a high inter-item reliability ( $a=0.87$ ). Independent Samples t-test

A $t$-test was performed to see if there was a statistically significant difference between liberals and conservatives and their respective scores on the symbolic homophobia scale. When running this test, equal variances cannot be assumed because there was a difference between the amount of liberals who responded $(N=39)$ and conservatives who responded $(N=7)$. With this taken into account, the analyses revealed a common trend that conservatives differ on the symbolic homophobia scale. Conservatives had a significantly lower score $(M=2.91, S D=0.65)$ as compared to liberals $(M=3.49, S D=0.42)$, $(t(44)=-2.27, p=0.058)$ whereas the lower the score, the more homophobic the score. In other words, conservatives have higher symbolic homophobic than liberals.

\section{Discussion}

Through the independent samples $t$-test results, Study 1 shows that there is a difference between political affiliation and symbolic homophobia. The data that was collected makes it clear that Conservatives are significantly more likely to be homophobic in 
comparison to Liberals. This fits directly with the expectations of the study, and provides a clear example of the political differences between the two ideologies. Although gay liberation has jumped great hurdles to move towards equality (Haber, 2009), this study shows that much work still needs to be done. Gay activists need to begin to call out Conservative leaders on their prejudice tendencies towards lesbian, gay, and bisexual persons. Psychologists should examine reasons why Conservatives have these underlying antigay views that this scale revealed in order to further combat homophobia.

With every new scale there are problems, whether with validity, reliability, or other weaknesses. The main issue with this scale is about external validity and the ability to generalize these results to the population at large. This survey was given to a known social network, which may have similar political ideologies. Because of this, making statements about all liberals or all conservatives may be difficult. This study will need to be retested with a new randomized sample of participants that captures a broader range of individuals. A reliability issue with the study is the amount of conservatives who participated in the survey $(N$ $=7$ ). Since this number is relatively small, it may be difficult to find the results reliable. If the test was redone with another small sample, the results could potentially be different simply from individual differences. When this study is repeated in the future, more conservative participants will need to be surveyed. Also, a larger, more randomized sample in general, is needed to be able to generalize more clearly about the population as a whole.

Another weakness, which was described by the participants in the comment section of the survey, was how a few of the questions were worded. The main question that seemed to pose some confusion to a few participants was "I believe being gay is fine as long as they keep it behind closed doors." The participants stated that they were not sure how to answer this question because they were fine with people being gay regardless if they decide to keep it open or behind closed doors. This question was to demonstrate that people who may be high in symbolic homophobia would say that being gay is fine as long as they are never exposed to it. Saying that you are okay with gay and lesbian people as long as they hide their sexuality would demonstrate symbolic homophobia. In Study 2, this question will have to be reworded so that participants know that disagreeing with this particular statement means that you are fine with people being open about being gay or lesbian.

In conclusion, although Study 1 has some limitations, it does still meet the two goals that were put fourth. The first goal that was met was to create a validate scale that assess symbolic homophobia. This can especially be seen in the high internal consistency $(\dot{a}=0.87)$. The second goal is that the scale seems to converge with the literature that Conservatives are more likely to be homophobic than Liberals (Linneman, 2004; Wood \& Bartkowski, 2004). Moreover, the results demonstrate that there is a relationship between political affiliation and symbolic homophobia as predicted by previous research.

\section{STUDY 2}

The aim of Study 2 goes beyond that of Study 1, and is designed to use the newly created symbolic homophobia scale in an experimental investigation of person perceptions of LGBT romantic couples. Researchers have demonstrated that an individual's level of homophobia lowers by having positive contact with a gay or lesbian person (Schope \& Eliason, 2000). The opposite has also been shown to be true. Research has reported that those with homophobic attitudes tend to lack association with gay or lesbian people (D'Augelli, 1989). In Study 2, the symbolic homophobia scale that was used in Study 1 will be used to test the effects of viewing either a vignette of a homosexual 
couple or that of a heterosexual couple. As the literature supports, Study 2 expects to show that being presented with a positive vignette of a homosexual couple will lower the research participant's symbolic homophobia score. This will be shown when comparing the mean score of symbolic homophobia to those participants who viewed the heterosexual couple vignette.

\section{Method}

\section{Participants}

The sample for this Study 2 comprised of 103 participants who took part in an online experiment. From these participants, $44.7 \%$ were males and $55.3 \%$ were females. For political affiliation, $25.2 \%$ reported being conservative and $74.8 \%$ reported being liberal. For sexual orientation, $52.4 \%$ reported being straight, $\quad 12.6 \%$ reported being Gay/Lesbian/Bisexual/Other, and 35\% did not report a sexual orientation. It should be noted that some participants' data were excluded from data analysis portion of this study. This included preview scenarios from the researcher $(N=4)$, not consenting to the survey $(N=1)$, and participants responding that they did not remember which personal vignette they saw in the beginning of the survey $(N=7)$. Also, the sample is considered a convenience sample because the participants were selected from a known group of people over a social media platform and group email servers. Further, the participants were not compensated in any way. Procedure

The data for the survey was collected over an online survey tool, Qualtrics. All of the participants were directed to a link that connected them to the online experiment. The first page asked the participants for their consent to participate in the experiment. After consenting, the individual was randomly presented with one of two written vignettes, either displaying a happy and stable gay couple or a happy and stable straight couple. A vignette is a written illustration that describes a situation to the participants. After reading one of the vignettes, they were then directed to answer the scale questions that were used in Study 1 about symbolic homophobia. The questions of the scale were randomized for each participant to counteract any ordering effects that could have arisen with the questions. Three demographic questions asked political affiliation (Liberal or Conservative), gender of the participants (Male, Female, or Transgender), and sexual orientation of the participants (Gay/Lesbian/Bisexual/Other or Straight). Also, a question was placed at the end that asked if the participant remembered what vignette they read about. There were three possible answers, one for each vignette and an "I don't remember" option (see Appendix B). If a participant said that they did not remember which vignette they read, they were excluded from data analyses $(N=7)$. The survey was distributed using an online social media site and was given haphazardly to a known social network.

\section{Measures}

Study 2 presented to the participants one of two situational vignettes. These two different situations were worded exactly the same in that both described a typical and positive relationship between two college seniors. The only difference between them was that one vignette displayed this relationship between two gay men and the other displayed it between a straight man and woman (see Appendix B). Everything else was kept exactly the same to control for any possible confounding variables. Participants were randomly presented with only one of the vignettes and then were asked to fill out the symbolic homophobia scale that was used in Study 1.

The symbolic homophobia scale was slightly modified for use in Study 2 . The scale still consisted of the same ten questions but some of the questions were changed to make them easier to understand. An example of this is in Study 1, an item was asked "I would become friends with someone regardless of 
their sexual identity." In Study 2, sexual identity was changed to "... regardless if they are gay or straight." Sexual identity is a nuanced term and may be difficult for some participants to understand easily. A few other minute changes were made in other items as well (see Appendices A and B). These items were asked on a 6-point scale from ranging from strongly agree to strongly disagree. With the participants' scores, a mean number was created that described the participants' symbolic homophobia. When creating this score, the six negative questions were reversed coded so that all the questions went in the same direction. In the end, the higher someone's composited score, the more homophobic they were. The lower someone's score, the less the participant was homophobic.

\section{Results \\ Chi-Square}

A Chi-square test was performed in order to examine whether males and females were distributed evenly across the two political affiliations, Conservative or Liberal. Neither males nor females were over-represented in the study in relation to political affiliation. The chi-square test reports that the relation between these variables was not significant across gender and that there was a proportionate amount of males and females, $\left(X^{2}(1, N=103)\right.$ $=.40, p=.57)$.

\section{Cronbach's Alpha}

To decide if the survey items for Study 2 still showed internal consistency and were reliable, a test of Cronbach's Alpha was performed. The symbolic homophobia scale showed a strong reliability of the questions ( $\dot{a}=$ $0.87)$.

\section{Independent Samples t-test}

A $t$-test was performed to see if there was a statistically significant difference between which vignette was presented to the participant (gay couple or straight couple) and their respective scores on the symbolic homophobia scale. Before running this test, it was decided to split the data and run a $t$-test including only heterosexual participants. LGB people, on the other hand, are not likely to express homophobia, regardless of the vignette they are presented with. Results show that those saw the gay couple vignette had a significantly lower score $(M=1.81, S D=$ 0.62 ) as compared to those who saw the straight couple vignette $(M=2.30, S D=1.10)$, $(t(47.26)=-2.08, p=0.043)$ whereas the lower the score, the less homophobic the score. In other words, reading the vignette about the gay couple, on average, lowered the participant's score on the symbolic homophobia scale.

\section{Discussion}

The results of Study 2 show that being presented with a vignette of a gay couple lowers the participant's symbolic homophobia score in comparison to being presented with a vignette of a straight couple. This fits directly with the expectations of Study 2, and provides a clear example that exposure to affirmative gay examples leads to more tolerance towards queer people. If a simple and short person vignette can significantly lower an individual's homophobia, imagine what affirmative and more powerful images of gay and lesbian couples could do to change the societal view on homosexuality at large. Potentially, Gay activists need to push for positive examples in the media and elsewhere. Psychologists also must learn how to most efficiently use positive gay illustrations to further combat homophobia.

Study 2 does have some problems with validity, reliability, and some other weaknesses. Like Study 1, the main issue with this scale is about external validity and the ability to generalize these results to the larger population. This experiment was conducted through a known social network, which may have similar ideologies and backgrounds. Because of this, making broad statements about all people may be difficult. Study 2 also has the same reliability issue with a low amount of conservatives who participated in the 
experiment $(N=26)$ as compared to liberals ( $N$ $=77$ ). As shown in Study 1, conservatives are more likely to be homophobic than liberals, and thus, in the future, it would be important to get a larger sample of conservatives. Also, a more randomized sample overall is necessary to be able to generalize more clearly about society as a whole.

Another weakness with Study 2 is with the relationship vignettes that were presented to the participants. The only two vignettes that were presented were a gay male couple and a straight couple. A question could be asked as to whether the mean scores on symbolic homophobia would be affected differently if the participants were presented with a lesbian couple vignette. It is a possibility that seeing a lesbian couple vignette would lower the participant's score on homophobia more than seeing a gay male couple. It is even possible that seeing a lesbian couple vignette would not affect the score at all. In Study 2, the answer to this is unknown. Another alternative vignette is one involving a couple where one or both of the individuals identifies as transgender. Transphobia though, is slightly different than homophobia, but is still an interesting possibility (Hill \& Willoughby, 2005).

In conclusion, although Study 2 does have some potential limitations, it still does fulfill its major goal. Study 2 showed that there is a direct relationship between being presented with a positive vignette of a gay couple and a participant's mean score on symbolic homophobia. This converges well with the literature that having positive contact with a gay or lesbian person lowers an individual's level of homophobia (Schope \& Eliason, 2000; D’Augelli, 1989).

\section{General Discussion}

The present two studies had the general purpose to further explore and investigate homophobia in a nuanced way. Study 1 validated a new scale to analyze homophobia in society in an underlying and symbolic way. It then showed a direct relationship between political affiliation and symbolic homophobia, whereas Conservatives are more likely to be homophobic than Liberals. Study 2 went beyond that of Study 1, and was designed to use the scale in an experimental investigation of person perceptions of queer people. Study 2 showed that there is a direct relationship between exposure of a positive vignette of a gay couple and the mean score on symbolic homophobia.

The two studies' results now need to be put together for what should be done moving forward. As shown by Study 1, gay activists need to mainly focus on those people who identify as Conservative in the fight for equality. Study 2 shows that a very simple person vignette can significantly lower an individual's homophobia. If gay activists can create positive and powerful images of gay and lesbian couples in the public spotlight, it could drastically change how society perceives homosexuality. Gay activists need to push for positive images in the popular media, the news, mass communications and other public spheres. On the psychological end of this topic, psychologists must intensely research why Conservatives have these underlying anti-gay views. Psychologists also must learn how to most efficiently use positive gay illustrations to further combat homophobia.

The fight against homophobia and heterosexism is extremely important. Discrimination in all of its terrible forms can no longer be tolerated. Homophobia creates an atmosphere where queer individuals feel ashamed and guilty simply from engaging in romantic relationships with someone of the same gender.an inborn trait. Homophobia has detrimental effects to the physical and mental wellbeing of those afflicted. With this, it is no wonder that gay and lesbian youths are two to three times more likely to attempt suicide than their straight peers (Nichols, 1999). Sadly, this number is probably an underestimate because 
of the consequences of being 'outed' as gay can

\section{Conclusion}

In conclusion, although these studies do further the research on homophobia, the biggest takeaway from this study is one thing, homophobia must be ended now. Here is an example of the horrors that is homophobia. In 1988, a 21-yearold gay student was robbed, pistol whipped and tortured because he was gay (Clarke et al., 2010). This student, Matthew Shepard, was told by his murders that they were gay too in order to lure Shepard into going with them. bring (Clarke et al., 2010).

The next morning, he was found by a cyclist tied to a fence and left to die. Matthew Shepard passed away in a hospital from severe head injuries a short time after. This should not have been and can no longer be tolerated. Homophobia must be eradicated in all of its forms. Until homoprejudice no longer exists, psychologists, researchers, gay activists, and allies must continuously work to protect and improve the lives of lesbian, gay, bisexual, transgender, and queer individuals

\section{References}

Aguinaldo, J. P. (2008). The social construction of gay oppression as a determinant of gay men's health: 'Homophobia is killing us'. Critical Public Health, 18(1), 87-96. doi:10.1080/09581590801958255

Ahmad, S., \& Bhugra, D. (2010). Homophobia: An updated review of the literature. Sexual and Relationship Therapy, 25(4), 447-455. doi:10.1080/14681994.2010.515206

American Psychiatric Association. (2000). Diagnostic and statistical manual of mental disorders (4th Ed.). Washington, DC.

Clarke, V., Ellis, S. J., Peel, E., \& Riggs, D. (2010). Lesbian, gay, bisexual, trans, \& queer psychology. Cambridge, England: Cambridge University Press.

D'Augelli, A.R. (1989) Lesbian's and gay men's experiences of discrimination and harassment in a university community. American Journal of Community Psychology, 17(3), 317-21 DOI: 10.1007/BF00931039

Haber, D. (2009). Gay aging. Gerontology \& Geriatrics Education, 30(3), 267-280. doi:10.1080/02701960903133554

Herek, G. M. (1988). Heterosexuals' attitudes toward lesbians and gay men: Correlates and gender differences. The Journal of Sex Research, 25, 451-477.

Hill, D. B., \& Willoughby, B. (2005). The development and validation of the Genderism and Transphobia Scale. Sex Roles, 53(7-8), 531-544.

Igartua, K. J., Gill, K. and Montero, R. (2003) Internalized homophobia: A factor in depression, anxiety, and suicide in the gay and lesbian population. Canadian Journal of Community Mental Health, 22(2), 15-30.

Kite, M. E. \& Deaux, K. (1986). Attitudes toward homosexuality: Assessment and behavioral consequences. Basic and Applied Social

Linneman, T. (2004). Homophobia and hostility: Christian conservatives reactions to the political and cultural progress of lesbians and gay men. Sexuality Research \& Social Policy: A Journal of the NSRC, 1(2), 56-76. doi:10.1525/srsp.2004.1.2.56

Nichols, S. L. (1999). Gay, lesbian, and bisexual youth: Understanding diversity and promoting tolerance in schools. The Elementary School Journal, 99(5), 505-519. doi: $10.1086 / 461938$

O'Brien, J. (2008). Complicating homophobia. Sexualities, 11(4), 496-512. 
doi:10.1177/136346070809345

Rabinowitz, J. L., Sears, D. O., Sidanius, J., \& Krosnick, J. A. (2009). Why do White Americans oppose race-targeted policies? Clarifying the impact of symbolic racism. Political Psychology, 30(5), 805-828. doi:10.1111/j.1467-9221.2009.00726.x

Schafer, C. E., \& Shaw, G. M. (2009). Trends - Tolerance in the United States. Public Opinion Quarterly, 73(2), 404-431. doi:10.1093/poq/nfp022

Schope, R. D., \& Eliason, M. J. (2000). Thinking versus acting: Assessing the relationship between heterosexual attitudes and behaviors towards homosexuals. Journal of Gay \& Lesbian Social Services: Issues in Practice, Policy \& Research, 11(4), 6992. doi:10.1300/J041v11n04_04

Wood, P. B., \& Bartkowski, J. P. (2004). Attribution style and public policy attitudes toward gay rights. Social Science Quarterly, 85(1), 58-74. doi:10.1111/j.00384941.2004.08501005. 


\section{Appendix A}

Study 1- Questionnaire survey given through the online survey tool Qualtrics

I believe gay relationships are essentially the same as straight relationships

O Strongly Agree

O Agree

O Disagree

O Strongly Disagree

Some gay people could be straight if they really wanted to be

O Strongly Agree

O Agree

O Disagree

O Strongly Disagree

I enjoy having friendships with gay and lesbian people

O Strongly Agree

O Agree

O Disagree

O Strongly Disagree

I feel uncomfortable when I see a gay couple holding hands

O Strongly Agree

O Agree

O Disagree

O Strongly Disagree

I would become friends with someone regardless of their sexual identity

O Strongly Agree

O Agree

O Disagree

O Strongly Disagree

I think discrimination towards Black Americans is worse than discrimination towards gay

Americans

O Strongly Agree

O Agree

O Disagree

O Strongly Disagree

I would feel uncomfortable if my child's teacher was gay

O Strongly Agree

O Agree

O Disagree

O Strongly Disagree

A business has the right to fire an employee because he or she is gay

O Strongly Agree

O Agree

O Disagree

O Strongly Disagree

I believe being gay is fine as long as they keep it behind closed doors

O Strongly Agree

O Agree 
Disagree
O Strongly Disagree
I believe marriage is marriage regardless of the two people's gender
O Strongly Agree
O Agree
O Disagree
O Strongly Disagree
What is your political affiliation?
O Conservative
O Liberal
What is your gender?
O Male
O Female
O Transgender
If you have any additional comments/feedback regarding the survey, please note them here.

\section{Appendix B}

Study 2 - Experimental conditions and symbolic homophobia items

This study is conducted by researchers at the University of Michigan. We are interested in your perceptions of sexual orientation. This study is completely anonymous and should take less than five minutes to complete. If you become uncomfortable at any point, you may exit the survey by closing your browser. To be eligible to participate in this survey you must be 18 years of age or older

O I consent to participate in this survey and I am 18 years of age or older

O I do not consent and do not want to participate in the survey

[Vignette 1] Please read the scenario below and answer the questions on the following page Steven is a 21-year-old college senior at the University of Michigan. He is majoring in Communications and a minor in International Studies. Steven enjoys playing his guitar and going to the gym. He is really active in several student groups at his University. Steven met James at a mutual friend's apartment party in their sophomore year and they have been dating ever since. James is also a senior at the same University and is finishing his major in English. James loves being outside, and especially enjoys hiking and hanging out with his friends.

Steven describes James as the perfect boyfriend. Their favorite date is simply watching a movie at Steven's apartment while cuddling and eating popcorn. Steven says, "We love spending time together, and I care very deeply for James. I couldn't ask for anyone more special." Steven and James have begun making plans for after they both graduate in the spring. They have started making plans to take a post-graduation vacation in Jamaica and then move in together. They both say they are excited to start a new chapter in their lives together.

Please press the button below to continue [Vignette 2] Please read the scenario below and answer the questions on the following page Steven is a 21-year-old college senior at the University of Michigan. He is majoring in Communications and a minor in International Studies. Steven enjoys playing his guitar and going to the gym. He is really active in several student groups at his University. Steven met 
Jessica at a mutual friend's apartment party in their sophomore year and they have been dating ever since. Jessica is also a senior at the same University and is finishing her major in English. Jessica loves being outside, and especially enjoys hiking and hanging out with her friends. Steven describes Jessica as the perfect girlfriend. Their favorite date is simply watching a movie at Steven's apartment while cuddling and eating popcorn. Steven says, "We love spending time together, and I care very deeply for Jessica. I couldn't ask for anyone more special." Steven and Jessica have begun making plans for after they both graduate in the spring. They have started making plans to take a post-graduation vacation in Jamaica and then move in together. They both say they are excited to start a new chapter in their lives together.

Please press the button below to continue

I believe gay relationships are essentially the same as straight relationships

O Strongly Agree

O Agree

O Somewhat Agree

O Somewhat Disagree

O Disagree

O Strongly Disagree

Some gay people could be straight if they really wanted to be

O Strongly Agree

O Agree

O Somewhat Agree

O Somewhat Disagree

O Disagree

O Strongly Disagree

I enjoy having friendships with gay and lesbian people

O Strongly Agree

O Agree

O Somewhat Agree

O Somewhat Disagree

O Disagree

O Strongly Disagree

I feel uncomfortable when I see a gay couple holding hands

O Strongly Agree

O Agree

O Somewhat Agree

O Somewhat Disagree

Disagree

O Strongly Disagree

I would become friends with someone regardless if they are gay or straight

O Strongly Agree

O Agree

O Somewhat Agree

O Somewhat Disagree

O Disagree

O Strongly Disagree 
I think discrimination towards Blacks is worse than discrimination towards people who are gay
O Strongly Agree
Agree
Somewhat Agree
O Somewhat Disagree
Disagree
O Strongly Disagree

I would feel uncomfortable if my child's teacher was gay
Strongly Agree
O Agree
Somewhat Agree
O Somewhat Disagree
Disagree
O Strongly Disagree

A business has the right to fire an employee because he or she is gay
O Strongly Agree
O Agree
Somewhat Agree
O Somewhat Disagree
Disagree
O Strongly Disagree

I believe being gay is fine only if they keep it behind closed doors
O Strongly Agree
O Agree
Somewhat Agree
Somewhat Disagree
Disagree
O Strongly Disagree

I think two adults of the same gender should have the right to get married
Strongly Agree
Agree
O Somewhat Agree
O Somewhat Disagree
Disagree
Strongly Disagree

If I had to choose one of the following, I would say I am

O Liberal

O Conservative

What is your gender?

O Male

O Female

Transgender

What is your sexual orientation?

O Straight

O Gay/Lesbian/Bisexual/Other

In the beginning of this survey, who did you read about? 


\section{O Steven and James \\ O Steven and Jessica \\ I don't remember}

